\title{
Injuries to the anterolateral ligament are observed more frequently compared to lesions to the deep iliotibial tract (Kaplan fibers) in anterior cruciate ligamant deficient knees using magnetic resonance imaging
}

\author{
Armin Runer ${ }^{1}$. Dietmar Dammerer ${ }^{1}$. Christoph Kranewitter ${ }^{3}$. Johannes M. Giesinger ${ }^{4}$. Benjamin Henninger ${ }^{2}$. \\ Michael T. Hirschmann ${ }^{5} \cdot$ Michael C. Liebensteiner $^{1}$
}

Received: 8 December 2020 / Accepted: 9 March 2021 / Published online: 26 March 2021

(c) The Author(s) 2021

\begin{abstract}
Purpose To determine the accuracy of detection, injury rate and inter- and intrarater reproducibility in visualizing lesions to the anterolateral ligament (ALL) and the deep portion of the iliotibial tract (dITT) in anterior cruciate ligament (ACL) deficient knees.

Methods Ninety-one consecutive patients, out of those 25 children (age $14.3 \pm 3.5$ years), with diagnosed ACL tears were included. Two musculoskeletal radiologists retrospectively reviewed MRI data focusing on accuracy of detection and potential injuries to the ALL or dITT. Lesion were diagnosed in case of discontinued fibers in combination with intra- or periligamentous edema and graded as intact, partial or complete tears. Cohen's Kappa and 95\% confidence intervals (95\% CI) were determined for inter- and intrarater reliability measures.

Results The ALL and dITT were visible in $52(78.8 \%)$ and $56(84.8 \%)$ of adult-and $25(100 \%)$ and $19(76.0 \%)$ of pediatric patients, respectively. The ALL was injured in 45 (58.5\%; partial: $36.4 \%$, compleate: $22.1 \%$ ) patients. Partial and comleate tears, where visualized in $21(40.4 \%)$ and $16(30.8 \%)$ adult- and seven (28.0\%) and one (4\%) peditric patients. A total of 16 (21.3\%; partial: $13.3 \%$, compleate: $8.0 \%$ ) dITT injuries were identified. Partal and complete lesions were seen in seven $(12.5 \%)$ and five $(8.9 \%)$ adult- and three (15.8\%) and one $(5.3 \%)$ pediatric patients. Combined injuries were visualized in nine $(12.7 \%)$ patients. Inter-observer $(0.91-0.95)$ and intra-observer $(0.93-0.95)$ reproducibility was high.

Conclusion In ACL injured knees, tears of the ALL are observed more frequently compared to lesions to the deep iliotibial tract. Combined injuries of both structures are rare. Clinically, the preoperative visualization of potentially injured structures of the anterolateral knee is crucial and is important for a more personalized preoperative planning and tailored anatomical reconstruction. The clinical implication of injuries to the anterolateral complex of the knee needs further investigation.

Level of evidence II.
\end{abstract}

Keywords Anterolateral ligament - ALL - Iliotibial tract - Iliotibial band Kaplan fibers - Anterior cruciate ligament rupture · ACL $\cdot$ MRI $\cdot$ Anterolateral knee complex $\cdot$ Knee $\cdot$ Intrarater reliability $\cdot$ Interrater reliability

Abbreviations

ITT Iliotibial tract

ALL Anterolateral ligament
MRI Magnetic resonance imaging

dITT Deep portion of the iliotibial tract
Michael C. Liebensteiner

michael.liebensteiner@tirol-kliniken.at

1 Department of Orthopaedics and Traumatology, Medical University of Innsbruck, Anichstrasse 35, 6020 Innsbruck, Austria

2 Department of Orthopaedic Surgery, Medical University Innsbruck, Innsbruck, Austria
3 Department of Radiology, Medical University Innsbruck, Innsbruck, Austria

4 Innsbruck Institute of Patient-Centered Outcome Research (IIPCOR), Innsbruck, Austria

5 Department of Orthopaedic Surgery and Traumatology, Kantonsspital Baselland (Bruderholz, Liestal, Laufen), Bruderholz, Switzerland 


\section{Introduction}

Recently, there has been an increased interest in the anterolateral extra-articular soft-tissue structures of the knee. In particular the anterolateral ligament (ALL) was popularized as an important stabilizer [5]. This triggered several investigations either on traceability of the ALL during cadaver dissection $[5,7,12,37,39,40,47]$, the biomechanical characteristics $[23,33,37,41,46]$ or the visibility of the ALL using magnetic resonance imaging (MRI) $[11,13-15,25$, $26,30,38,48]$.

Several previous studies dealt with MRI-visibility of the ALL both in healthy and ACL injured knees [11, 13-15, 25, $26,30,38,48]$. A recent systematic review reported a high variability in visualizing the intact ALL (51-100\%) as well as identifiying potential injuries to the structure (10.7-98\%) when using MRI [1].

While most of the above-mentioned authors promote the ALL as a main anterolateral knee stabilizer opposing excessive internal tibial rotation and subluxation, others doubt the relevance of the ALL in providing anterolateral knee stability, putting more emphasis on the role of the deep portions of the iliotibial tract, including the so called Kaplan fiber complex [18, 22, 35]. The deep portion of the iliotibial tract (dITT) was first described in 1958 by Kaplan et al. and consists of two distinct parts: the deep attachments of the ITT to the distal femur (Kaplan fibers, KF) and the capsuloosseous layer of the ITT (COL) [20, 29, 34, 49]. The Kaplan fibers have been further distinguished in proximal and distal supracondylar fibers connecting the ITT to the postero-lateral femur approximately $28-41 \mathrm{~mm}$ above the lateral femoral epicondyle [16, 17, 29, 42]. Recent articles examining both healthy individuals and knee specimens reported good MRI visibility of the dITT ranging between 60.6 and $100 \%$ [2, 3, 28, 32].

Up to date, no study has yet investigated the variability and reliability in diagnosing lesions to both the ALL and the dITT in adult and pediatric patients with ACL deficient knees.

The aim of the present study was to answer the following study questions: (1) What is the visibility of the ALL and DITT in adult and pediatic ACL deficient knees using MRI? (2) What is the injury rate of the ALL and the dITT in adult and pediatic ACL deficient knees? (3) What is the inter- and intra-observer reproducibility in detecting lesions to the ALL and dITT in ACL deficient knees using MRI?

\section{Materials and methods}

Ethical approval was obtained from the ethical committee of the Medical University of Innsbruck (AN20 15-0269 355/4.18). The analysis was conducted in accordance with the ethical standards of the Declaration of Helsinki.

\section{Patients}

MRI data of 91 consecutive sujects, out of those 25 children, with clinical and radiological diagnosed ACL rupture were retrospectively reviewed focusing on the accuracy of detection and potential injuries to the ALL or dITT. All diagnoses were made by sports-medicine trained orthopaedic surgeons and two musculosceletal radiologists, respectively. Prior to inclusion an in depth clinical history was obtained and medical records were checked for previous knee injuries or surgeries. Patients were excluded in case of metallic material such as screws or plates around the knee, motion artifacts or different MRI protocols.

\section{Radiological analysis}

All MRIs were obtained using an identical protocol. Patients were examined in supine position with extended knees using a dedicated 15-channel knee coil. The following sequences were used for the 3.0 T Scanner (Avanto/Skyra, Siemens, Erlangen, Germany): coronal T1-weighted images (TE 10/13, TR 696/522, SL $3 \mathrm{~mm}$ ); coronal PD-weighted images with fat-saturation (TE 40/38, TR 4100/3230, SL $3 \mathrm{~mm}$ ); sagittal PD-weighted images with fat-saturation (TE 39/38, TR 3000/3710, SL $3 \mathrm{~mm}$ ) and axial PD-weighted images with fat-saturation (TE 31/37, TR 3010/3100, SL 3.5/3 mm). Two trained and certified musculoskeletal radiologists (HB, $\mathrm{KC}$ ) with dedicated MRI experience analyzed coronal, sagittal and axial MRI sets of all patients using the imaging viewer Impax EE (Agfa Health Care N.V., Mortsel, Belgium). Before the start of the analysis, a specialist in the field of anterolateral knee anatomy lectured and briefed both radiologists in a private cadaver dissection classe All relevant lateral and anterolateral structures of the knee were dissected and studied.

Both radiologist were blinded to the clinical findings of the patients. Each radiologist performed the analysis twice with an interval in between greater than 2 weeks. For ALL diagnostic, a low-signal ligamentous structure originating from the postero-proximal region of the lateral femoral epicondyle, running in an anterodistal direction deep to the ITT, crossing the lateral collateral ligament in the proximal third and inserting on the anterlateral tibia between Gerdy's tubercle and the fibular head, was searched. For the diagnostic of 
the dITT an extraarticular, low-signal band structure connecting the ITT to the proximal ridge of the distal femur was scouted. Detailed definition of both structures as well as diagnostic criteria for MRI identification are reported in Table 1.

Each radiologiest categorized both structures first as either visible or non visible and subsequentely as intact, partial or complete injured. A complete ALL or dITT lesion was diagnosed in case of discontinued fibers in combination with intra- or peri-ligamentous edema. A partial ruptur was defined as an alteration of the normal fiber contiguity but without a clear ligament disruption. Abnormal intraligamentous signal and surrounding periligamentous edema may be present in partial ligament ruptures. In case an ALL injury was diagnosed, further subspecification in proximal- (above meniscus level) and distal- (below meniscus level) intraligamentous lesions as well as tibial avulsion fractures (Segond type) were made. For ITT lesions, a further subclassification in (a) proximal lesions of the deep ITT (Kaplan fiber complex) or (b) lesions to the COL of the ITT [20, 29, 34, 49] was conducted. The COL was defined according to previous recommendations as deep fibers running from the region of the Kaplan fiber complex to the anterolateral tibia [9, 20, 29, 34, 49]. After data analysis and inter-and intra-observer calculation, discrepant radiological findings were reviewed, discussed and a consensus was found between both radiologists. The results of the consensus are reported in the result section and Table 3.

\section{Statistical analysis}

Descriptive statistics and statistical analysis were performed using SPSS v. 22 (IBM Corp.). Cohen's Kappa and 95\% confidence intervals $(95 \% \mathrm{CI})$ were determined as a measure of inter- and intra-observer reproducibility. A value of 0.70 for Cohen's Kappa was considered as threshold for substantial reproducibility [27]. Sample size considerations were based on power analysis for a Pearson correlation as an approximation for the Cohen's Kappa coefficient. Power analysis for Cohen's Kappa was not available in common power analysis software packages. An observed correlation coefficient of 0.83 in a sample of 60 cases was sufficient to demonstrate exceedance of the 0.70 threshold with alpha $=0.05$ and beta $=0.20$ (one-sided). Power analysis was done with $\mathrm{G}^{*}$ Power 3.1.9.2 [8]. The following scale of measurement agreement was applied: $0-0.2$, slight; $0.21-0.4$, fair; $0.41-0.6$, moderate; $0.61-0.8$, substantial; $0.81-1$, almost perfect [27].

\section{Results}

A total of 66 adult (35 female) and 25 children (10 female) patients with clinical and radiological diagnosed complete ACL ruptures were included in the study. Patient demographics and additional injuries are reported in Table 2.
Table 1 Diagnostic criteria for MRI identification of the ALL and deep portion of the ITT [9]

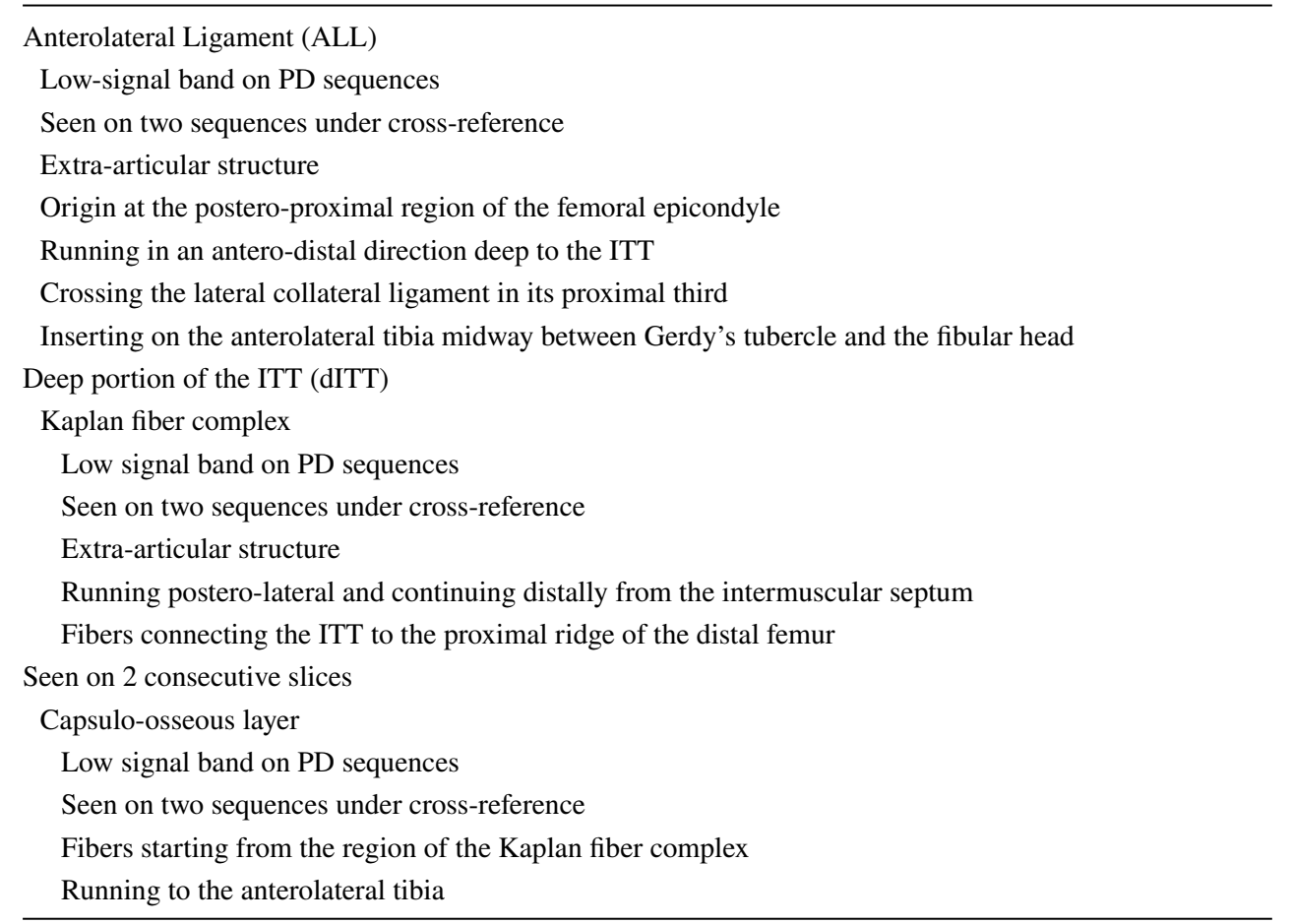

ALL Anterolateral Ligament, ITT Iliotibial Tract, $P D$ proton density 
Table 2 Patients demographics

\begin{tabular}{llll}
\hline & Adult patients & Pediatric patient & Total \\
\hline$N$ & 66 & 25 & 91 \\
Gender (m/f) & $31 / 35$ & $15 / 10$ & $46 / 45$ \\
Age (mean \pm SD) & $38.4 \pm 14.1$ & $14.3 \pm 3.5$ & $31.8 \pm 16.3$ \\
BMI & $27.1 \pm 19.8$ & $27.1 \pm 15.5$ & $27.1 \pm 18.7$ \\
Additional injuries ${ }^{\mathrm{a}}$ & & & \\
$\quad$ Medial meniscus & 28 & 8 & 34 \\
$\quad$ rupture & & & \\
$\quad$ Lateral meniscus & 11 & 3 & 14 \\
$\quad$ rupture & & & 31 \\
$\quad$ MCL injury & 24 & 7 & 11 \\
$\quad$ LCL injury & 9 & 2 & 20 \\
Chondromalacia & 20 & 0 & 2 \\
PCL injury & 0 & 2 & \\
\hline
\end{tabular}

$m / f$ male/female, $B M I$ body mass index, $M R I$ magnetic resonance imaging, $M C L$ medial collateral ligament, $L C L$ lateral collateral ligament, $P C L$ posterior cruciate ligament

${ }^{a}$ Injuries as radiological reported

\section{Visibility}

In 77 (84.6\%) of all patients the ALL was visible. The deep femoral attachments of the dITT (Kaplan fiber complex) were identified in 75 (82.4\%) of the cases. The COL of the ITT was not seen in any patient. For further subclassification in adult and pediatric patients see Table 3 .

\section{Injury rate}

An injury to the ALL as seen in 45 (58.5\%) of the patients. Out of those were 17 (22.1\%) complete- and 28 (36.4\%) partial ALL tears, respectively. In none of the cases a tibial avulsion (Segond lesion) was detected. An lesion to the dITT was visualized in $16(21.3 \%)$ of the patients with six $(8.0 \%)$ beeing complete and $10(13.3 \%)$ beeing partial ruptures. Combined injuries of both the ALL and the dITT was reported in nine (12.7\%) patients. For further subclassification in adult and pediatric patients see Table 2. Examples of intact and ruptured structures are presented in Figs. 1, 2 and 3.

\section{Reliability analysis}

Detailed inter- and intra-observer data are presented in Table 4. Overall inter-observer agreement was high with calculated Cohen's Kappa values of 0.95 (95\% CI 0.89-1.00) for proximal ALL injuries, 0.91 (95\% CI 0.82-0.99) for distal ALL lesions and 0.94 (95\% CI 0.86-1.00) for ruptures of the Kaplan

Table 3 Visibility and rupture frequencies for the anterolateral ligament (ALL) and the deep portion of the iliotibial tract (dITT) in adult and pediatric patients with ACL deficiency

\begin{tabular}{|c|c|c|c|c|c|c|c|c|c|}
\hline & \multicolumn{3}{|c|}{ Adult patients $(n=66)$} & \multicolumn{3}{|c|}{ Pediatric patients $(n=25)$} & \multicolumn{3}{|c|}{ Total patients $(n=91)$} \\
\hline & $\begin{array}{l}\text { Visible } \\
n(\%)\end{array}$ & $\begin{array}{l}\text { Complete tear } \\
n(\%)\end{array}$ & $\begin{array}{l}\text { Partial tear } \\
n(\%)\end{array}$ & $\begin{array}{l}\text { Visible } \\
n(\%)\end{array}$ & $\begin{array}{l}\text { Complete tear } \\
n(\%)\end{array}$ & $\begin{array}{l}\text { Partial tear } \\
n(\%)\end{array}$ & $\begin{array}{l}\text { Visible } \\
n(\%)\end{array}$ & $\begin{array}{l}\text { Complete tear } \\
n(\%)\end{array}$ & $\begin{array}{l}\text { Partial tear } \\
n(\%)\end{array}$ \\
\hline \multicolumn{10}{|l|}{$\begin{array}{l}\text { Anterolateral } \\
\text { ligament }^{\mathrm{a}}\end{array}$} \\
\hline Proximal part & $60(90.9)$ & $10(16.7)$ & $19(31.7)$ & $25(100)$ & $1(4)$ & $4(16)$ & $85(93.4)$ & $11(12.9)$ & $23(27.1)$ \\
\hline Distal part & $55(83.3)$ & $13(23.6)$ & $7(12.7)$ & $25(100)$ & $0(0)$ & $4(16)$ & $80(87.9)$ & $13(16.3)$ & $11(13.8)$ \\
\hline $\begin{array}{l}\text { Tibial avulsion } \\
\text { (Segond) }\end{array}$ & $66(100)$ & $0(0)$ & $0(0)$ & $25(100)$ & $1(4)$ & $0(0)$ & $91(100)$ & $1(1.1)$ & $0(0)$ \\
\hline \multicolumn{10}{|l|}{ Illiotibial tract ${ }^{\mathrm{a}}$} \\
\hline $\begin{array}{l}\text { Deep femoral } \\
\text { attachment (KFC) }\end{array}$ & $56(84.8)$ & $5(8.9)$ & $7(12.5)$ & $19(76.0)$ & $1(5.3)$ & $3(15.8)$ & $75(82.4)$ & $6(8.0)$ & $10(13.3)$ \\
\hline $\begin{array}{l}\text { Capsulo-osseous } \\
\text { layer }\end{array}$ & n.a & n.a & n.a & n.a & n.a & $\mathrm{n} . \mathrm{a}$ & $\mathrm{n} . \mathrm{a}$ & $\mathrm{n} . \mathrm{a}$ & n.a \\
\hline $\begin{array}{l}\text { Anterolateral liga- } \\
\text { ment (any part) }\end{array}$ & $52(78.8)$ & $16(30.8)$ & $21(40.4)$ & $25(100)$ & $1(4)$ & $7(28.0)$ & 77 (84.6) & $17(22.1)$ & $28(36.4)$ \\
\hline $\begin{array}{l}\text { Iliotibial tract (any } \\
\text { part) }^{\mathrm{a}}\end{array}$ & $56(84.8)$ & $5(8.9)$ & $7(12.5)$ & $19(76.0)$ & $1(5.3)$ & $3(15.8)$ & $75(82.4)$ & $6(8.0)$ & $10(13.3)$ \\
\hline $\begin{array}{l}\text { Torn ALL (any part) } \\
\text { and dITT (any } \\
\text { part) }\end{array}$ & $52(78.8)$ & $2(3.8)$ & $5(9.6)$ & $19(76.0)$ & $0.0)$ & $2(10.5)$ & $71(78.0)$ & $2(2.8)$ & $7(9.9)$ \\
\hline
\end{tabular}

Percentages of tear frequencies are reported. The absolute numbers are reported in relation to the number of visible cases [excluding "Tibial avulsion (Segond)]

n.a. not applicable, $A L L$ anterolateral ligament, $d I T T$ deep portion of the Iliotibial Tract, $K F$ Kaplan fiber complex

${ }^{a}$ Displayed as number and percentage; ${ }^{b}$ applicable, if in both anatomical structures (ALL and dITT) at least one part is injured 
Fig. 1 Coronal (a), axial (b) and sagittal (c) PD-weighted fat-saturated image with a suprameniscal tear of the ALL (red arrow) and a complete tear of the Kaplan fiber complex (yellow arrow) indicated by the wavy appearance and surrounding edema green arrow $=$ superficial ITT; blue arrow = lateral collateral ligament
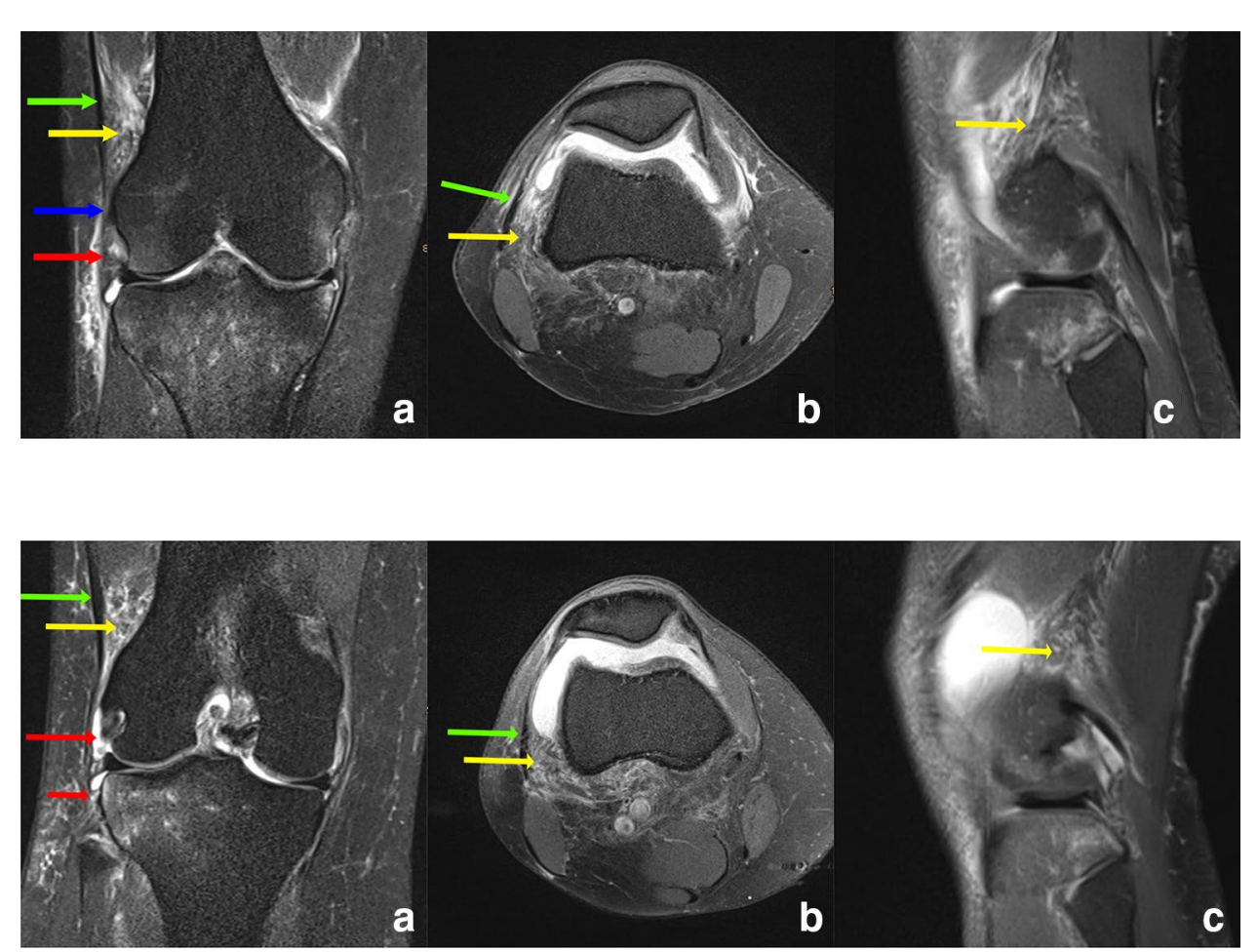

Fig. 2 Coronal (a), axial (b) and sagittal (c) PD-weighted fatsaturated image with a complete lesion of the Kaplan fiber complex (yellow arrow) and complete tear of the suprameniscal (long red arrow) and inframeniscal (short red arrow) ALL. There is diffuse edema around the Kaplan fiber complex green arrow $=$ superficial ITT

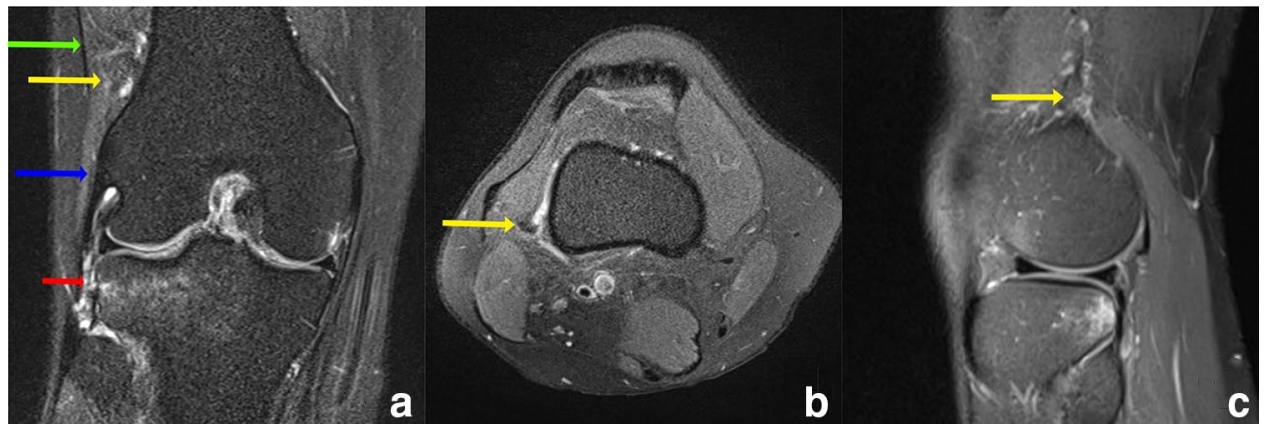

Fig. 3 Coronal (a), axial (b) and sagittal (c) PD-weighted fatsaturated image with a lesion to the inframeniscal ALL (short red arrow) but intact Kaplan fiber complex (yellow arrow). There is diffuse edema around the ALL, while no signal alteration is visible next to the Kaplan fiber complex green arrow = superficial ITT; blue arrow $=$ lateral collateral ligament fiber complex. The COL was not visible in any patients. For each of the investigated parameters absolute agreement between the observers was at least $94.0 \%$. Calculated intraobserver reliability values were 0.95 (95\% CI 0.89-1.00) for proximal ALL lesions, 0.93 (95\% CI 0.85-1.00) for distal ALL lesions and 0.94 (95\% CI 0.87-1.00) for lesions of the Kaplan fibers complex. For each of the investigated parameters absolute agreement between the two time points was at least 0.95 .

\section{Discussion}

The most important finding of the present study was, that tears of the ALL (58.5\%) are observed more frequently compared to lesions to the dITT (21.3\%) in ACL deficient knees. Combined injuries of both structures are rare 
Table 4 Inter- and intraobserver reproducibility results for the tear rates of the ALL and the dITT

\begin{tabular}{|c|c|c|c|c|}
\hline & \multicolumn{2}{|c|}{ Interobserver reliability } & \multicolumn{2}{|c|}{ Intraobserver reliability } \\
\hline & $\begin{array}{l}\text { Cohen's Kappa } \\
(95 \% \text { CI })\end{array}$ & $\begin{array}{l}\text { Absolute agree- } \\
\text { ment }(\%)\end{array}$ & $\begin{array}{l}\text { Cohen's Kappa } \\
(95 \% \text { CI })\end{array}$ & $\begin{array}{l}\text { Absolute } \\
\text { agreement } \\
(\%)\end{array}$ \\
\hline \multicolumn{5}{|l|}{ Anterolateral ligament } \\
\hline Proximal part & $\begin{array}{l}0.95 \\
(0.89-1.00)\end{array}$ & 97.1 & $0.95(0.89-1.00)$ & 97.1 \\
\hline Distal part of ALL & $\begin{array}{l}0.91 \\
(0.82-0.99)\end{array}$ & 94.0 & $0.93(0.85-1.00)$ & 95.5 \\
\hline Tibial avulsion (Segond) & n.c & 100 & n.c & 100 \\
\hline \multicolumn{5}{|l|}{ Iliotibial tract } \\
\hline $\begin{array}{l}\text { Deep femoral attachments } \\
\text { (Kaplan fibers) }\end{array}$ & $0.94(0.86-1.00)$ & 97.1 & $0.94(0.87-1.00)$ & 97.1 \\
\hline Capsulo-osseous layer & n.c & 100 & n.c & 100 \\
\hline
\end{tabular}

Inter- and intra-observer reproducibility results for the different parts of the anterolateral ligament (ALL) (proximal, distal tibial avulsion) and the deep iliotibial tract (ITT) structures (deep attachments of the ITT to the distal femur, capsulo-osseous layer of the ITT)

95\% CI 95\% confidence interval, n.c. not calculated
(12.7\%). Both the ALL and dITT can be asses with high inter- and intra-observer reliability when using MRI.

Poor clinical outcomes, functional knee instability and an increased risk for osteoarthritis due to persistent anterolateral rotatory instability (ALRI) after ACL reconstruction led to an increased interest in the anterolateral knee structures, predominantly to the ALL and the deep portion of the ITT. However, biomechanical results are inconsistent whether one or the other structure provides more anterolateral stability to the knee joint [6, 9, 22, 24, 35, 36, 43, 44]. A fact, which is also reflected in the number of available different extra-articular reconstruction techniques to address high-grade rotatory instability. While some authors advocate ACL surgery in combination with an anatomical ALL reconstruction [19, 45], others prefer a lateral tenodesis by inserting the graft more proximal at the femur, mimicking the deep structures of the ITT rather than the ALL [4, 31].

Contradictory knowledge exists about the true injury rates as well as the validity and reproducibility in assessing lesions to the ALL and the dITT using MRI. A more profound radiological understanding, however, is crucial for a more personalized preoperative planing and more tailored anatomical reconstruction of these structures.

Regarding the ALL, an increased but heterogeneous body of evidence has emerged lately with tear rates ranging between 10.7 and $98 \%$ in ACL deficient knees [1]. Intraand inter-observer reliabilities vary between $0.04-0.86$ and $0.33-1.0$, respectively [1]. The present findings of $22.1 \%$ complete- and $36.4 \%$ partial ALL lesions in patients with ACL rupture are in the middle of the injury ranges stated in the literature. Contrary, intra- and intra-rater reliabilities were rather high, ranging between 95.5-97.1 and 94.0-97.1, respectively. These high agreements within and between both rather might be best explained by the high experience level of both fellowship-trained musculoskeletal radiologist and the usage of a modern $3 \mathrm{~T}$ scanner with a dedicated 15-channel knee coil.

Besides numerous studies analyzing the ALL, little knowledge exists about the injury incidence of the deep portion of the ITT. This is somewhat surprising, since those structures have been described anatomically much earlier than the ALL, are believed to work as an agonist to the ACL (like a horseshoe) and are emphasized by some authors to play a more important role than the ALL in providing anterolateral rotatory stability [10, 20, 22, 29, 34, 49]. Batty et al. [2] examined 50 healthy knees using MRI and identified the dITT in $96 \%$ of the cases on sagittal images and $76 \%$ in the axial view. Inter-observer reliability assessment revealed slight to moderate agreement with Kappa values ranging between 0.1 and 0.5 . In a recently published study of our study group, the Kaplan fiber complex could be visualized in $60.6 \%$ of healthy knees with high inter- and intra-observer reliabilities [28]. Berthold et al. identified the proximal and distal fibers of the ITT in $100 \%$ and $90 \%$ of specimen knees using MRI and in $100 \%$ of cadaver dissection [3].

Little and contrary evidence exists about the incidence rate of dITT injuries in ACL deficient patiens (Table 5). Van Dyck et al. [50] examined 69 patients reporting assosciated injuries to the Kaplan fibers in 33\% (30\% periligamentous edema, $3 \%$ partial tear, $0 \%$ compleate tear) and injuries to the ALL in $57 \%$ of the patients ( $17 \%$ periligamentous edema, $32 \%$ patial tear, $7 \%$ compleate tear). Khanna et al. [21] reported in a cohort of 20 patients an injury rate of $82 \%$ to the proximal- and $29 \%$ to the distal fibers, respectively. Recently, Marom et al. [32] identiefied with moderate to good inter- and intrarater reliablity injuries to the Kaplan 


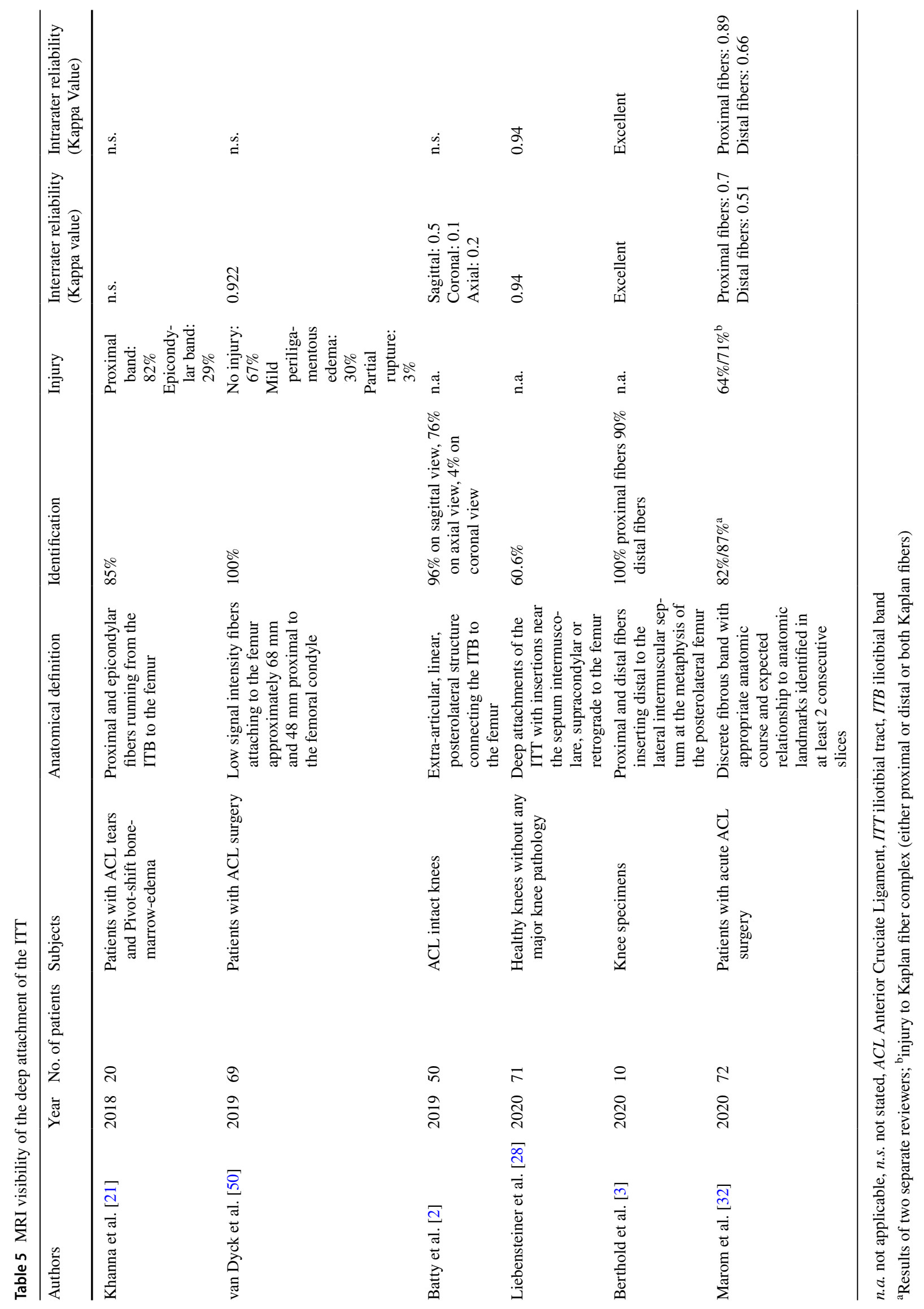


fiber complex in $51 \%$ of the examined patients. However, no clear differentiation between periligamentous edema, partial or compleate tear was made. In the present study the reported injury rate for dITT lesions was $21.3 \%$, with $8.0 \%$ beeing complete- and $13.3 \%$ beeing partial ruptures, respectively. In addition to any previous research, injury data for both structures within the same patient are reported. A combined lesion of both structures occurred in $12.7 \%$ of the patients, with $2.8 \%$ beeing partial- and $9.9 \%$ being complete ruptures. Compared to adults, a lower injury rate for both total- and partial lesions was observed in pediatric patients.

Marom et al. [32] stated several potential factors being responsible for the differences in the rate of visualizing injuries to the dITT. Different MRI devices, MRI parameters and examination protocols as well as differences in the training and experience of examiners might influence outcomes when detecting lesions to the anterolateral ligamentous structures of the knee. In the present study PD-weighted fat satured axial and coronal images were preferred by both fellowship trained musculoskeletal radiologist for visualizing both the ALL and the dITT injuries.

The present data indicate that concomitant ALL or dITT injuries are common in ACL deficient knees; however, a combined lesion of both structures is rather rare. This information might be of special clinical relevance in the treatment of rotatory unstable knees, where an anatomical extra-articular, antero-lateral reconstruction is planned and, therefore, a preoperative in-depth understanding of the injured structures required.

This study has some limitations. First, this was a retrospective study bearing a selections bias. Second, MRI scans, where taken within the first 6 week post trauma. During this time, the hemorrhage surrounding the anterolateral soft tissue structures might have reabsorbed thus complicating the visualization. Moreover, there are no validated diagnostic criteria to detect lesions to the ALL and especially the dITT. To overcome this knowledge gap, general principles for diagnosing ligamentous and soft-tissue injuries were used. The major strengths of the present study were strict inclusion criteria, a large cohort of patients, the examination of pediatric patients, and the use of a modern 3-T MRI scanner. Additionally, all examinations were performed by two specialized and certified musculo-skeletal radiologists with more than 15 years of experience. Finally, the incidence as well as inter- and intra-observer reproducibility in detecting lesions of the ALL and dITT in the same patient was assessed for the first time.

Clinically, the preoperative visualization of potentially injured structures of the anterolateral knee is crucial and is important for a more personalized preoperative planning and tailored anatomical reconstruction. Further biomechanical and clinical studies are needed to better understand the impact of injuries to the anterolateral complex of the knee.

\section{Conclusion}

In ACL injured knees, tears of the ALL (58.4\%) are observed more frequently compared to lesions to the deep iliotibial tract, including the Kaplan fiber complex (21.3\%). Combined injuries of both structures are rare. Injuries to the ALL and the deep portion of the ITT can be assessed with high inter- and intra-observer agreement using MRI.

Acknowledgements We thank Mrs. M.H. Margreiter for professional English language editing.

Funding Open access funding provided by University of Innsbruck and Medical University of Innsbruck.

\section{Declarations}

Conflict of interest Each author certifies that he or she has no commercial associations (e.g., consultancies, stock ownership, equity interest, patent/licensing arrangements, etc.) that might pose a conflict of interest in connection with the submitted article.

Funding No funding.

Ethics approval and consent to participate Ethical approval (AN2015$0269355 / 4.18$ ) was obtained from the ethic committee of the Medical University of Innsbruck (Ethikkommission der Medizinischen Universität lnnsbruck).

Open Access This article is licensed under a Creative Commons Attribution 4.0 International License, which permits use, sharing, adaptation, distribution and reproduction in any medium or format, as long as you give appropriate credit to the original author(s) and the source, provide a link to the Creative Commons licence, and indicate if changes were made. The images or other third party material in this article are included in the article's Creative Commons licence, unless indicated otherwise in a credit line to the material. If material is not included in the article's Creative Commons licence and your intended use is not permitted by statutory regulation or exceeds the permitted use, you will need to obtain permission directly from the copyright holder. To view a copy of this licence, visit http://creativecommons.org/licenses/by/4.0/.

\section{References}

1. Andrade R, Rebelo-Marques A, Bastos R, Zaffagnini S, Seil R, Ayeni OR et al (2019) Identification of normal and injured anterolateral ligaments of the knee: a systematic review of magnetic resonance imaging studies. Arthroscopy 35(1594-1613):e1591

2. Batty L, Murgier J, O'Sullivan R, Webster KE, Feller JA, Devitt BM (2019) The Kaplan fibers of the iliotibial band can be identified on routine knee magnetic resonance imaging. Am J Sports Med 47:2895-2903

3. Berthold DP, Willinger L, Muench LN, Forkel P, Schmitt A, Woertler K et al (2020) Visualization of proximal and distal Kaplan fibers using 3-dimensional magnetic resonance imaging and anatomic dissection. Am J Sports Med. https://doi.org/10. 1177/0363546520919986363546520919986

4. Buda R, Ruffilli A, Di Caprio F, Ferruzzi A, Faldini C, Cavallo $M$ et al (2013) Allograft salvage procedure in multiple-revision 
anterior cruciate ligament reconstruction. Am J Sports Med 41:402-410

5. Claes S, Vereecke E, Maes M, Victor J, Verdonk P, Bellemans J (2013) Anatomy of the anterolateral ligament of the knee. J Anat 223:321-328

6. Delaloye JR, Hartog C, Blatter S, Schlappi M, Muller D, Denzler $D$ et al (2020) Anterolateral ligament reconstruction and modified lemaire lateral extra-articular tenodesis similarly improve knee stability after anterior cruciate ligament reconstruction: a biomechanical study. Arthroscopy. https://doi.org/10.1016/j.arthro.2020. 03.027

7. Dodds AL, Halewood C, Gupte CM, Williams A, Amis AA (2014) The anterolateral ligament: anatomy, length changes and association with the segond fracture. Bone Jt J 96-B:325-331

8. Faul F, Erdfelder E, Lang AG, Buchner A (2007) G*Power 3: a flexible statistical power analysis program for the social, behavioral, and biomedical sciences. Behav Res Methods 39:175-191

9. Getgood A, Brown C, Lording T, Amis A, Claes S, Geeslin A et al (2019) The anterolateral complex of the knee: results from the International ALC Consensus Group Meeting. Knee Surg Sports Traumatol Arthrosc 27:166-176

10. Golan E, Tisherman R, Byrne K, Diermeier T, Vaswani R, Musahl V (2019) Anterior cruciate ligament injury and the anterolateral complex of the knee-importance in rotatory knee instability? Curr Rev Musculoskelet Med 12:472-478

11. Gossner J (2014) The anterolateral ligament of the knee-visibility on magnetic resonance imaging. Rev Bras Ortop 49:98-99

12. Helito CP, Demange MK, Bonadio MB, Tirico LE, Gobbi RG, Pecora JR et al (2013) Anatomy and histology of the knee anterolateral ligament. Orthop J Sports Med 1:2325967113513546

13. Helito CP, Demange MK, Helito PV, Costa HP, Bonadio MB, Pecora JR et al (2015) Evaluation of the anterolateral ligament of the knee by means of magnetic resonance examination. Rev Bras Ortop 50:214-219

14. Helito CP, Helito PV, Bonadio MB, Pecora JR, Bordalo-Rodrigues $\mathrm{M}$, Camanho GL et al (2015) Correlation of magnetic resonance imaging with knee anterolateral ligament anatomy: a cadaveric study. Orthop J Sports Med 3:2325967115621024

15. Helito CP, Helito PV, Costa HP, Bordalo-Rodrigues M, Pecora JR, Camanho GL et al (2014) MRI evaluation of the anterolateral ligament of the knee: assessment in routine 1.5-T scans. Skeletal Radiol 43:1421-1427

16. Herbst E, Albers M, Burnham JM, Fu FH, Musahl V (2017) The anterolateral complex of the knee. Orthop J Sports Med 5:2325967117730805

17. Herbst E, Albers M, Burnham JM, Shaikh HS, Naendrup JH, Fu FH et al (2017) The anterolateral complex of the knee: a pictorial essay. Knee Surg Sports Traumatol Arthrosc 25:1009-1014

18. Huser LE, Noyes FR, Jurgensmeier D, Levy MS (2017) Anterolateral ligament and iliotibial band control of rotational stability in the anterior cruciate ligament-intact knee: defined by tibiofemoral compartment translations and rotations. Arthroscopy 33:595-604

19. Ibrahim SA, Shohdy EM, Marwan Y, Ramadan SA, Almisfer AK, Mohammad MW et al (2017) Anatomic reconstruction of the anterior cruciate ligament of the knee with or without reconstruction of the anterolateral ligament. Am J Sports Med. https:// doi.org/10.1177/0363546517691517363546517691517

20. Kaplan EB (1958) The iliotibial tract; clinical and morphological significance. J Bone Jt Surg Am 40-A:817-832

21. Khanna M, Gupte C, Dodds A, Williams A, Walker M (2019) Magnetic resonance imaging appearances of the capsulo-osseous layer of the iliotibial band and femoral attachments of the iliotibial band in the normal and pivot-shift ACL injured knee. Skelet Radiol 48:729-740
22. Kittl C, El-Daou H, Athwal KK, Gupte CM, Weiler A, Williams A et al (2016) The role of the anterolateral structures and the ACL in controlling laxity of the intact and ACL-deficient knee. Am J Sports Med 44:345-354

23. Kittl C, El-Daou H, Athwal KK, Gupte CM, Weiler A, Williams A et al (2016) The role of the anterolateral structures and the ACL in controlling laxity of the intact and ACL-deficient knee: response. Am J Sports Med 44:NN15-18

24. Kittl C, Halewood C, Stephen JM, Gupte CM, Weiler A, Williams A et al (2015) Length change patterns in the lateral extra-articular structures of the knee and related reconstructions. Am J Sports Med 43:354-362

25. Klontzas ME, Maris TG, Zibis AH, Karantanas AH (2016) Normal magnetic resonance imaging anatomy of the anterolateral knee ligament with a T2/T1-weighted 3-dimensional sequence: a feasibility study. Can Assoc Radiol J 67:52-59

26. Kosy JD, Mandalia VI, Anaspure R (2015) Characterization of the anatomy of the anterolateral ligament of the knee using magnetic resonance imaging. Skelet Radiol 44:1647-1653

27. Landis JR, Koch GG (1977) The measurement of observer agreement for categorical data. Biometrics 33:159-174

28. Liebensteiner M, Runer A, Kranewitter C, Nachtigal P, Giesinger J, Dammerer D et al (2020) MRI visibility of the anterolateral ligament and the deep structures of the iliotibial tract. J Exp Orthop $7: 25$

29. Lobenhoffer P, Posel P, Witt S, Piehler J, Wirth CJ (1987) Distal femoral fixation of the iliotibial tract. Arch Orthop Trauma Surg 106:285-290

30. Macchi V, Porzionato A, Morra A, Stecco C, Tortorella C, Menegolo M et al (2016) The anterolateral ligament of the knee: a radiologic and histotopographic study. Surg Radiol Anat 38:341-348

31. Marcacci M, Zaffagnini S, Giordano G, Iacono F, Presti ML (2009) Anterior cruciate ligament reconstruction associated with extra-articular tenodesis: a prospective clinical and radiographic evaluation with 10- to 13-year follow-up. Am J Sports Med 37:707-714

32. Marom N, Greditzer HG, Roux M, Ling D, Boyle C, Pearle AD et al (2020) The incidence of Kaplan fiber injury associated with acute anterior cruciate ligament tear based on magnetic resonance imaging. Am J Sports Med 48:3194-3199

33. Monaco E, Ferretti A, Labianca L, Maestri B, Speranza A, Kelly MJ et al (2012) Navigated knee kinematics after cutting of the ACL and its secondary restraint. Knee Surg Sports Traumatol Arthrose 20:870-877

34. Müller W (1983) The knee: form, function and ligament reconstruction. Springer, Berlin, pp 43-47

35. Noyes FR, Huser LE, Jurgensmeier D, Walsh J, Levy MS (2017) Is an anterolateral ligament reconstruction required in ACLreconstructed knees with associated injury to the anterolateral structures? A robotic analysis of rotational knee stability. Am J Sports Med 45:1018-1027

36. Noyes FR, Huser LE, Levy MS (2017) Rotational knee instability in ACL-deficient knees: role of the anterolateral ligament and iliotibial band as defined by tibiofemoral compartment translations and rotations. J Bone Jt Surg Am 99:305-314

37. Parsons EM, Gee AO, Spiekerman C, Cavanagh PR (2015) The biomechanical function of the anterolateral ligament of the knee. Am J Sports Med 43:669-674

38. Porrino J Jr, Maloney E, Richardson M, Mulcahy H, Ha A, Chew FS (2015) The anterolateral ligament of the knee: MRI appearance, association with the Segond fracture, and historical perspective. AJR Am J Roentgenol 204:367-373

39. Rahnemai-Azar AA, Miller RM, Guenther D, Fu FH, Lesniak BP, Musahl V et al (2016) Structural properties of the 
anterolateral capsule and iliotibial band of the knee. Am J Sports Med 44:892-897

40. Runer A, Birkmaier S, Pamminger M, Reider S, Herbst E, Kunzel $\mathrm{KH}$ et al (2016) The anterolateral ligament of the knee: a dissection study. Knee 23:8-12

41. Saiegh YA, Suero EM, Guenther D, Hawi N, Decker S, Krettek C et al (2015) Sectioning the anterolateral ligament did not increase tibiofemoral translation or rotation in an ACL-deficient cadaveric model. Knee Surg Sports Traumatol Arthrosc 25(4):1086-1092

42. Sayac G, Goimard A, Klasan A, Putnis S, Bergandi F, Farizon F (2021) The anatomy of Kaplan fibers. Arch Orthop Traum Surg 141(3):447-454

43. Smith PA, Thomas DM, Pomajzl RJ, Bley JA, Pfeiffer FM, Cook JL (2019) A biomechanical study of the role of the anterolateral ligament and the deep iliotibial band for control of a simulated pivot shift with comparison of minimally invasive extra-articular anterolateral tendon graft reconstruction versus modified lemaire reconstruction after anterior cruciate ligament reconstruction. Arthroscopy 35:1473-1483

44. Sonnery-Cottet B, Lutz C, Daggett M, Dalmay F, Freychet B, Niglis L et al (2016) The involvement of the anterolateral ligament in rotational control of the knee. Am J Sports Med 44:1209-1214

45. Sonnery-Cottet B, Thaunat M, Freychet B, Pupim BH, Murphy CG, Claes S (2015) Outcome of a combined anterior cruciate ligament and anterolateral ligament reconstruction technique with a minimum 2-year follow-up. Am J Sports Med 43:1598-1605
46. Spencer L, Burkhart TA, Tran MN, Rezansoff AJ, Deo S, Caterine $S$ et al (2015) Biomechanical analysis of simulated clinical testing and reconstruction of the anterolateral ligament of the knee. Am J Sports Med 43:2189-2197

47. Stijak L, Bumbasirevic M, Radonjic V, Kadija M, Puskas L, Milovanovic D et al (2016) Anatomic description of the anterolateral ligament of the knee. Knee Surg Sports Traumatol Arthrosc 24:2083-2088

48. Taneja AK, Miranda FC, Braga CA, Gill CM, Hartmann LG, Santos DC et al (2015) MRI features of the anterolateral ligament of the knee. Skelet Radiol 44:403-410

49. Terry GC, Norwood LA, Hughston JC, Caldwell KM (1993) How iliotibial tract injuries of the knee combine with acute anterior cruciate ligament tears to influence abnormal anterior tibial displacement. Am J Sports Med 21:55-60

50. Van Dyck P, De Smet E, Roelant E, Parizel PM, Heusdens CHW (2019) Assessment of anterolateral complex injuries by magnetic resonance imaging in patients with acute rupture of the anterior cruciate ligament. Arthroscopy 35:521-527

Publisher's Note Springer Nature remains neutral with regard to jurisdictional claims in published maps and institutional affiliations. 